\title{
Bhagyamma Gajawada Letters In Economics
}

\author{
Satish Gajawada \\ The Son of Bhagyamma Gajawada and Prabhakar Gajawada \\ India
}

\begin{abstract}
This work is dedicated to my mother "Bhagyamma Gajawada". "Bhagyamma Gajawada Letters In Economics" is the extended version of work titled "Smile Theory of Everything" published in International Proceedings of Economics, Development and Research (IPEDR). Please read the entire paper to understand the "Bhagyamma Gajawada Letters In Economics".
\end{abstract}

Keywords: Mother, Economics, Everything, Economics Of Everything, Kindness, Smile, Bhagyamma Gajawada

\section{INTRODUCTION}

There are many ways in which one can bring smile on the face of others. A human can imagine the feel of bringing smile on others face simply by looking his own smile with the help of a mirror. Summer season may be very hot but some methods may be used for smile creation. These methods can bring coolness and interest even during summer season. Smile creation is a wonderful field of research. The beauty of this smile creation field is that smile is the final result that one wants no matter what someone does i.e., whether we do "bits, bytes and protocols" or "profits, losses and margins" ultimately it is to smile and make others smile.

Section 2 gives Truth which is first format. Some methods for smile creation is $2^{\text {nd }}$ format shown in third section. Smiles discovered or created during summer 2011 are described in Section 4. Application of Smile computing method during a festival is explained in fifth section. Section 6 shows methods I used for getting happiness and satisfaction during a birthday.

\section{TRUTH}

Some call GOD, some call ghost, some call TheHuman etc. The terminology may change but there exists something powerful in this nature. You will understand better only when you experience it. Forgive me if I made any mistake while delivering the TRUTH to you.

\section{SOME METHODS FOR SMILE CREATION}

1) When your friend asks Do you have good movies? and you instead of saying No think of another friend who collects good movies and go to that friend as if you want to see movies and ask that friend who has movies Please give me your hard disk to copy movies and he may say NO and then you convince him that it will generate lot of happiness for another friend and request him for 5 minutes and finally he will give them and take those and give them to friend who asked you and believe in me he will smile and say thank you and you will feel like swimming(not just flying) in the skyJ

2) Your friend may go out of station and suddenly he needs something urgent to be done by you which he cannot do it from there and so you decide to go out but then it may be very hot outside and you may feel like saying sorry I can $t$ do it to your friend and somehow make your brain sleep and without any thinking just go and no matter how 
difficult it is complete the task and call your friend and say that you have done it and he will say Thank you! Thank you! and you will feel like Yahoo! J

3) You have a colourful shirt in your room but you are not using it and it is just a shirt which is nothing to you but it can make a worker with low salary and a sincere person smile and giving that shirt to him can make him feel like Hurrah! Watching that smile you will be able to know the true meaning of life and why you are here and what you should do J

4) Decide to giveup something you like so that your friends resolutions come true. Your giving up and love towards your friend surely one day will make your friend achieve what he was trying to do. Like if your friend has an addiction and wants to giveup and he was unable to do so then you show him by givingup something for him so that he knows that it s not a big issue to giveup these addictions]

5) If you are staying away from home and you went home recently and again you get holidays for 3-4 days then most of time you will be spending in travelling like in train or bus and effectively you will stay very less time at home and so better option may be is to not to go home and that saved money of travelling expenses by not going home can be used for noble cause like donating football, bag and many such things to many child and believe in me it is just travelling expenses to you but that small amount of money can bring lot of happiness in the life of poor children and after donating you will feel like I am king of this day J

6) You may have attended a course last year and purchased a good book and that you are not using it but your another friend is very much interested in that book and he told you few times that book is very good and this is a great chance to you to give that book to him and see the wonderful smile on his face and after watching that scene you will feel like Hurrah!

\section{WOW! SUMMER 2011!}

One day you may sit in class and your professor may ask "why don't you give a voluntary presentation on this topic?" Then your brain may say "there are no marks! There are no marks! for this and don't say yes " and your heart may say "It is a rare chance to make whole class smile for around 15 minutes" and then you kick the brain and give chance to heart and say "Yes! I will give a voluntary presentation" and later prepare it in such a way that you can make people smile and go and give presentation for free and when you see people laughing and your inner voice says Yes! Yes!

One day when you are cleaning your room with water...it may happen that two ants are stuck between water and you may see that and your brain may say "let them die who cares" and just ignore it and take a paper and keep it near ants which are in between water and then two ants climb the paper and believe in me you have saved their life! Hurrah!

You may have studied a course and you have that textbook and you don't need it anymore and one of your friend needs it. Maybe he never asked the book but call him and ask "do you need this book?" and he says yes and you just go to his room as if you want the book from him and just give him the book and come back and while coming back don't forget to watch the wonderful smile on his face! Awesome!

Oneday you maybe walking from room to mess and in between a person may ask "Do you have any unwanted papers? I will buy it ". You just go to your room and find all the papers and you may have some unwanted books and while coming back another person may ask "are you giving these papers away for person standing outside? Can I take them?" and then you give half 
papers to him and remaining papers to person standing outside. Don't take money from them because it is not a big deal for you.Wow! you created two smiles :):-

Oneday it may happen that results are declared and your friend is failed and he has to go out from college and then you just go to computer centre and then find some inspirational quote or something and then print on a paper and stick it on thick paper and cut it in proper shape and you give it to him. It is not a big deal whether you go for parties with him or not but when he is in trouble you must be there with him or atleast try something for making him feel good. Yeah it is difficult as first you must go to computer centre and search for few hours and then you must go out and print and cut and then giving... doing this is difficult but not doing this is much more difficult if he is really your friend!

Your friend maybe in trouble and asks you to give him company for sometime by watching movie with him. It may happen that you have some work. If possible arrange it for someother time and spend fewhours with him because he feels he is not alone and someone like you is there with him when he is in troubles.

Oneday you maybe eating some sweet in mess and your friend may ask "Take one more sweet and I want only $40 \%$ and rest you must eat" and it may happen that you don't want to eat but imagine you are giving him happiness by bringing sweet and eating with him. At the end don't forget to feel the feeling of happiness $(;)$

Maybe you have come across some post and some great heart wants to clear the confusion and you know the answer and then just reply to post as if your best friend is in trouble and clear confusion because it may have big effect on the other side $\odot$ Wow $\odot$

Maybe your friend is in trouble and asks you to come for a walk for an hour and this is the moment you must be there with him and listen to him and go for walk with him and for sometime slap the brain and kick it off which always says "me me me.." and listen to heart which says "help him help him" and this is one of the wonderful kindness acts you have done ();

Maybe your exams are going on and one of your friend who is sincere and hard working hard asks you "Can you come to library and I will ask doubts in between and will not disturb much" and it is a rare opportunity and just go and clear small doubts small numer of times and your small help may help him pass the hurdle! Awesome!

Maybe you have struggled hard to install some software last year and your friends may have project presentation this year and they may ask "Can I take your computer for demo?" and then you give it to them and it may happen you must stay without computer for 2 days and the more interesting thing is you have got an opportunity to help and that is awesome and your help can make a big difference.

Maybe you went for eating and you found your senior hungry and he don't have any money and then just pay for him because filling the stomach of hungry man is one of the most wonderful things in this world! Wow!

Maybe your friend is out of station and results are displayed and he is calling you again and again for knowing his result and it may happen that you are not in department and it is very hot and then just go as if you want to watch your own grades and note his grades and call him and give information and he will say Thank you! And after putting call off don't forget to dance!Hurrah! 
At night when you just slept..you may get call from a friend and your brain may say "don't lift don't lift" and your heart may say "your friend may be in problem and that's why he called you so late even he knows you are sleeping" and believe in heart and go and listen to him and give your views and with this you have helped a friend in problems! Awesome!

Maybe some anonymous person wants to improve himself and wants to exchange thoughts then whenever he mails read it properly and give thoughts because that may help him change and do some good and it is not a big deal whether you are doing good or that anonymous person is doing good but the thing is good is finally happening and hence you read his mails properly and your replies make him feel someone is there like him and he feels happy and feeling his feeling makes you feel happy! Mind Blowing!

Maybe you went for bath and you found you are using so much water then from that time keep a look on howmuch water you are using and use it with care because water is too precious to be wasted!

Oneday your friend may say "I have returned 2 books in library and 1 book is still with me and I have to return" and after few days when you are returning your books then call him and ask whether you can return his book and with great heart he may give an opportunity to help him by saying "Yes!" or he may say it is gone somewhere. By this you have made your friend feel someone is there for him and you have found an opportunity to help! Great!

Another student who don't know what error is there is program may send you mail saying "it is urgent and if you see this then kindly mail me error in program" and it is such a wonderful opportunity to help and create coolness in hot summer and make it interesting! Cool!

\section{FESTIVAL BASED ALGORITHM FOR SMILE CREATION}

There are many ways to implement this algorithm and the following implementation was tried. Step 1: Found a wonderful colourful shirt in the room. Step 2: Realized I just wear T-shirts all the time and giving away this colourful shirt doesn't make much damage. Step 3: Found a worker who is good and sincere and also observed that one colourful shirt can make his holi colourful. Step 4: Brain will send signals "Are you giving this shirt to him. Are you gone mad?" and it will give 1000 reasons not to give that shirt to worker. Step 5: Slap the Brain and give the control to heart and give 100000 reasons why you want to give the shirt to worker. Step 6: This is the mind blowing step where you give the shirt and you will find a big smile on the face on worker and also he will say "Thank you" and you will feel like swimming (not just flying) in the sky.

\section{BIRTHDAY BASED METHOD FOR OPTIMAL SMILE CREATION}

On Birthdays we may spend thousands and sometimes lakhs in some cases. What I did on my birthday based method is I changed few parameter values. Generally self parameter is more and others in need parameter is less. What I did is I tried to decrease self by some amount and increase others in need and distributed money to others in need also. I found many smiles and that created smile on my face. This overall thing may be termed as "Smile Effect" where each human created smile on the face of other humans. I am unable to express happiness because somethings in life cannot be expressed or published but they can only be felt.

\section{CONCLUSION}

There are many ways to create smiles. People might call with different names but there exists something powerful in nature. Follow your heart/brain. Heart and brain both are important. Forgive me if I made any mistakes. 
ACKNOWLEDGEMENTS

Thank you to everyone and everything for directly or indirectly helping me and making me what I am Today

\section{References}

Satish Gajawada, "Smile Theory of Everything”. International Proceedings of Economics Development and Research, 2012. 